\title{
MEMBANGUN GENERASI UNGGUL MELALUI PENYULUHAN DAN PELATIHAN KEWIRAUSAHAAN BAGI PEMUDA KARANG TARUNA RT / RW: 004/013 KEBON DUREN KELURAHAN CIPUTAT
}

\author{
${ }^{1}$ Abdul Khoir, ${ }^{2}$ Suhandi, ${ }^{3}$ Agus Sudarsono, ${ }^{4}$ Erni Rahmawati, ${ }^{5}$ Purwanti \\ Dosen Fakultas Ekonomi Universitas Pamulang \\ Email : $\underline{1}$ dosen02490@unpam.ac.id
}

\begin{abstract}
ABSTRAK
Tujuan kegiatan pengabdian kepada masyarakat ini adalah untuk menumbuhkan jiwa berwirausaha pemuda karang taruna RT/RW : 004013 Kebon Duren Ciputat dengan pemanfaatan media sosial. Metode yang digunakan pada Pengabdian Kepada Masyarakat ini berupa ekspositori yaitu penyampaian materi secara verbal dan inquiry yaitu pembelajaran yang menekankan pada proes berpikir kritis dan analisis terkait dengan keilmuan manajemen pemasaran dengan pemahaman mendalam terkait materi dalam menentukan masa depan terlebih pada dunia wirausaha.

Dengan penyuluhan kewirausahaan ini diharapkan dapat meningkatkan pengetahuan, pemahaman dan keterampilan pemuda karang taruna rt/rw : 004/013 Kebon Duren Ciputat tentang berwirausaha serta pemanfaatan media sosial sebagai promosi usaha.
\end{abstract}

\section{Kata Kunci : Wirausaha, Media Sosial, Promosi Usaha (Bisnis)}

\section{PENDAHULUAN}

Kekayaan alam yang dimiliki oleh negara Indonesia harus dikelola dengan baik sehingga manfaatnya dapat dirasakan oleh seluruh rakyat Indonesia. Hal ini sesuai dengan apa yang diamanatkan dalam Undang - Undang Dasar tahun 1945 Pasal 33 Ayat 1 sampai dengan ayat 5 tentang prinsip ekonomi Indonesia serta pengelolaan kekayaan alam negara. Keberhasilan pengelolaan sumber daya alam tidak terlepas dari sumber daya manusia sebagai penggerak, pengelola sumber daya alam yang dimiliki. Dengan demikian, perlu adanya peningkatan SDM yang unggul untuk dapat mengelola SDA agar manfaatnya dapat dirasakan oleh seluruh rakyat Indonesia.

Karang Taruna Pemuda Rt/Rw : 004/013 Kebon Duren Kelurahan Ciputat merupakan salah satu wujud dari upaya peningkatan SDM untuk dapat bersaing, berinovasi serta dapat memberikan manfaat bagi lingkungan sekitar. Berbagai macam kegiatan telah dilakukan untuk mendorong, memotivasi anggota Karang Taruna Rt; 004/013 untuk dapat meningkatkan SDM yang dimiliki agar dapat bermanfaat bagi diri sendiri dan juga tentunya manfaat tersebut dapat dirasakan oleh lingkungan sekitar. Berbagai upaya telah dilakukan untuk peningkatan SDM pemuda karang taruna diantaranya dengan kegiatan penyuluhan bahaya narkoba, pelatihan pembuatan barang kerajinan tangan, sosialisasi bank sampah serta 
kegiatan lainnya, akan tetapi minat ataupun respon dari pemuda karang taruna masih rendah, mereka lebih memilih untuk terjun pada dunia kerja dengan persaingan yang sangat ketat serta membutuhkan keahlian tertentu, sementara tingkat pendidikan formal yang dimiliki hanya sampai tingkat SMP dan SMA. Dengan demikian tidak sedikit dari mereka belum mendapatkan pekerjaan yang nantinya akan berpengaruh kepada rendahnya perekonomian keluarga.

Berdasarkan permasalahan tersebut, maka perlu adanya jalan keluar untuk dapat meningkatkan perekonomian keluarga pemuda karang taruna yaitu dengan cara berwirausaha.

\section{METODE PELAKSANAAN KEGIATAN}

Metode pelaksanaan dalam kegiatan program pengabdian kepada masyarakat ini diawali dengan melakukan pendekatan kepada ketua Pemuda Karang Taruna RT : 004/013 Kebon Duren Ciputat. Dari hasil survey awal melalui wawancara dengan Ketua Pemuda Karang Taruna RT :004/013 Kebon Duren Ciputat, disampaikan pada dasarnya adalah masih banyaknya pemuda karang taruna yang belum memiliki pekerjaan/penghasilan tetap yang dapat meningatkan ekonomi keluarga.

Adapun metode pelaksanaan program pengabdian kepada masyarakat sebagai berikut:

1. Tahap Pemilihan Lokasi Pengabdian. Tahap pemilihan lokasi pengabdian kepada masyarakat tentu harus mempertimbangkan banyak hal., salah satunya adalah kebutuhan masyarakat yang merupakan objek dari pengabdian.

2. Tahap Pengusulan. Setelah tim pengusul melakukan observasi awal dan sudah mengidentifikasi permasalahan pada objek pengabdian kepada masyarakat, maka dapat ditentukan temanya atau judulnya. Selanjutnya berdasarkan tema tersebut disusunlah proposal pengabdian kepada masyarakat yang diajukan melalui program Sintias.

3. Tahap Pengumpulan data. Pengumpulan data yaitu mengumpulkan data di lokasi pengabdian dengan melakukan konsultasi, observasi, wawancara, dan dokumentasi dengan menentukan strategi pengumpulan data yang dipandang tepat untuk menentukan tema atau fokus serta pendalaman data pada proses pengumpulan data berikutnya.

4. Tahap Pelaksanaan Pengabdian Kepada Masyarakat. Tahap pelaksanaan pengabdian kepada masyarakat merupakan tahap pelaksanaan penyuluhan tentang kewirausahaan untuk meningkatkan SDM pemuda karang taruna kebon duren ciputat. Pada. tahap ini tim pengusul melakukan penyuluhan sesuai tema terkait, melakukan sharing pendapat, dan mengidentifikasi kebutuhan materi yang diinginkan dan penawaran program pengabdian kepada masyarakat berkelanjutan di masa-masa yang akan datang.

5. Tahap Pelaporan Hasil Pengabdian. Pada tahan pelaporan hasil pengabdian kepada masyarakat ini merupakan laporan serangkaian kegiatan mulai dari survey pra-pengabdian hingga pelaporan kegiatan. (6) Tahap Publikasi. Hasil 
atau laporan kegiatan pengabdian kepada masyarakat akan dipublikasikan sebagai luaran dari kegiatan pengabdian kepada masyarakat ini.

\section{HASIL DAN PEMBAHASAN}

Pemuda Karang Taruna kebon Duren beranggotakan seluruh pemuda/i yang berdomisili di lingkungan RT : 004/013 Kebon Duren Ciputat yang berasal dari berbagai latar belakang pendidikan, ekonomi yang berbeda-beda. Akan tetapi kebanyakan dari anggota karang taruna berlatar belakang pendidikan dan ekonomi rendah sehingga banyak dari mereka yang belum memliki pekerjaan/penghasilan tetap. Hal ini disebabkan oleh beberapa faktor, diantaranya adalah sulitnya mendapat pekerjaan karena lapangan pekerjaan yang sedikit, ketatnya persaingan untuk mendapatkan pekerjaan serta rendahnya keterampilan yang dimiliki untuk berwirausaha.

Berdasarkan studi lapangan yang telah dilakukan oleh tim pengabdian kepada masyarakat Universitas Pamulang, maka perlu adanya upaya untuk mendorong atau memberikan motivasi, pemahaman serta keterampilan dalam berwirausaha serta pemanfaatan media sosial sebagai sarana promosi usaha/bisnis yang pada akhirnya diharapkan dapat meningkatkan perekonomian keluarga anggota karang taruna.

Proses pembelajaran kewirausahaan semata-mata diarahkan untuk berwirausaha saja tetapi berwirausaha yang sesuai dengan bidang ilmunya (relevansi). Dengan demikian dalam prespektif ini, yang menjadi fokus dalam kewirausahaan ini adalah upaya

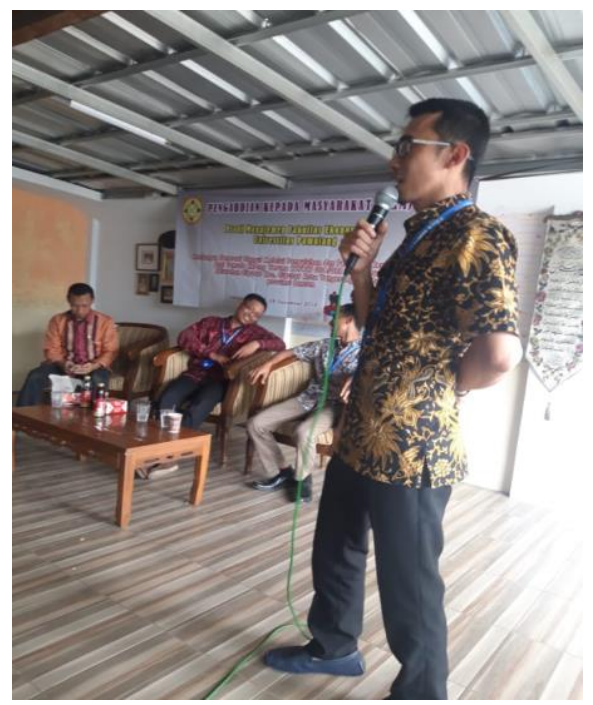

Gambar 1. Penyampaian Materi oleh Salah Satu Dosen menemukan peluang, melakukan kajian dan mengimplementasikan dalam pasar. Hal ini dikenal sebagai inovasi yaitu sebuah ide kreatif yang diimplementasikan baik dalam bentuk produk, jasa atau proses bisnis yang lain.

Walaupun diantara para ahli ada yang lebih menekankan kewirausahaan pada peran pengusaha kecil, namun sifat inipun sebenarnya dimiliki oleh orangorang yang berprofesi di luar wirausahawan. Jiwa kewirausahaan ada pada setiap orang yang menyukai perubahan, pembaharuan, kemajuan dan tantangan, apapun profesinya.

Dengan demikian, ada enam hakekat pentingnya Kewirausahaan (Daryanto:2012), yaitu:

1. Kewirausahaan adalah suatu nilai yang diwujudkan dalam perilaku yang dijadikan sumber daya, tenaga penggerak, tujuan, siasat, kiat, proses dan hasil bisnis. 
2. Kewirausahaan adalah suatu nilai yang dibutuhkan untuk memulai sebuah usaha dan mengembangkan usaha.

3. Kewirausahaan adalah suatu proses dalam mengerjakan sesuatu yang baru (kreatif) dan berbeda (inovatif) yang bermanfaat dalam memberikan nilai lebih.

4. Kewirausahaan adalah kemampuan untuk mencip takan sesuatu yang baru dan berbeda.

5. Kewirausahaan adalah suatu proses penerapan kreatifita dan keinovasian dalam memecahkan persoalan dan menemukan peluang untuk memperbaiki kehidupan usaha.

6. Kewirausahaan adalah usaha menciptakan nilai tambah dengan jalan mengkombinasikan sumber-sumber melalui cara-cara baru dan berbeda untuk memenangkan persaingan.

Kewirausahaan pada hakikatnya adalah sifat, ciri dan watak seseorang yang memiliki kemauan dalam mewujudkan gagasan inovatif kedalam dunia nyata secara kreatif. Inti dari kewirausahaan adalah kemampuan menciptakan sesuatu yang baru dan berbeda. Kreatifitas adalah berfikir sesuatu yang baru, inovasi adalah bertindak melakukan sesuatu yang baru.

\section{KESIMPULAN DAN SARAN}

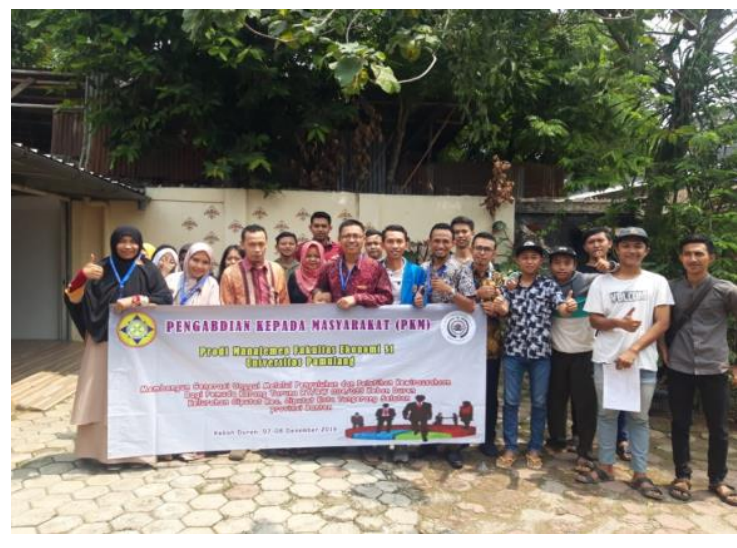

Gambar 2. Foto Bersama

Dengan adanya penyuluhan tentang kewiraushaan pada Pemuda Karang Taruna Kebon Duren Ciputat diharapkan dapat meningkatkan motivasi serta memberikan ide/gagasan baru dalam menciptakan peluang usaha dilingkungan sekitar serta dapat memanfaatkan teknologi berupa media sosial sebagai sarana promosi usaha/bisnis.

Solusi untuk memberikan penyuluhan kewirausahaan untuk meningkatkan perekonomi keluarga ini sebenarnya juga masih belum cukup harus dilakukan pelatihan dan pembinaan secara berkelanjutan sebagai pembekalan berwirausaha, masih banyak solusi yang bisa diberikan untuk peningkatan perekonomi keluarga. Secara berkelanjutan tim pengusul akan terus melakukan binaan untuk berbagi pengetahuan dan pengalaman dalam kemasan pengabdian kepada masyarakat. Tim pengusul pengabdian kepada masyarakat akan terus berupaya meningkatkan produktivitas masyarakat dengan menyesuaikan potensi masyarakat setempat. 


\section{DAFTAR PUSTAKA}

A Buchori, 2014, Manajemen Pemasaran dan Pemasaran Jasa, Alfabeta, Bandung. A Kaplan \& Michael Haen Lein, 2010, User Of The World, Unite! The Challenges and Opportunities Of Social Media, Business Horizons.

A Sobarna, S Hambali, S Sutiswo, D Sunarsi. (2020). The influence learning used $\mathrm{ABC}$ run exercise on the sprint capabilities. Jurnal Konseling dan Pendidikan 8 (2), 67-71

A Sudarsono, D Sunarsi. (2020). Pengaruh Kualitas Pelayanan Dan Varian Produk Terhadap Keputusan Pembelian Pada Laboratorium Klinik Kimia FarmaBintaro. Value: Jurnal Manajemen dan Akuntansi 15 (1), 16-26

Azra, Azyumardi.Pendidikan Islam di Era Globalisasi: Peluang dan Tantangan, [EDUKASI: Jurnal Penelitian Pendidikan Agama dan Keagamaan 2017] 6.4 .

D Prasada, S Sarwani, M Catio. (2019). Pengaruh Kompensasi Dan Lingkungan Kerja Terhadap Kinerja Karyawan Pada PT. Mitra Adiperkasa, Tbk. Jurnal Manajemen, Bisnis dan Organisasi (JUMBO) 3 (3), 195-207

D Sunarsi. (2014). Pengaruh Gaya Kepemimpinan, Motivasi dan Disiplin Kerja Terhadap Kinerja Pendidik. Universitas Pamulang

Daryanto. 2012, Pendidikan Kewirausahaan, Gava Media. Yogyakarta.

Depdiknas. 2006. Kurikulum Tingkat Satuan Pendidikan (KTSP), Depdiknas, Jakarta.

Diah Ningrum, UNISIA, Vol. XXXVII No. 82 Januari 2015. Edukasia Islamika : Volume 1, Nomor 1, Desember 2016/1438

Gumilar, I., Sunarsi, D. (2020). Comparison of financial performance in banking with high car and low car (Study of banks approved in the kompas 100 index for the period 2013-2017). International Journal of Psychosocial Rehabilitation. Volume 24 - Issue 7

Jasmani, J., \& Sunarsi, D. (2020). The Influence of Product Mix, Promotion Mix and Brand Image on Consumer Purchasing Decisions of Sari Roti Products in South Tangerang. PINISI Discretion Review, 1(1), 165-174.

Kotler, Philip dan Gary, Amstrong, 2016, Prinsip-prinsip Pemasaran. Edisi 13.Jilid 1, Erlangga, Jakarta.

L Nofiana, D Sunarsi. (2020). The Influence of Inventory Round Ratio and Activities Round Ratio of Profitability (ROI). JASa (Jurnal Akuntansi, Audit dan Sistem Informasi Akuntansi) 4 (1), 95-103

L Nofiana, D Sunarsi. (2020). The Influence of Inventory Round Ratio and Activities Round Ratio of Profitability (ROI). JASa (Jurnal Akuntansi, Audit dan Sistem Informasi Akuntansi) 4 (1), 95-103

Maddinsyah, A., Sunarsi, D., Hermawati, R., Pranoto. (2020). Analysis of location selection effect on the user decision that influcence the success of the service business of micro, small and medium enterprise (MSME) in bandung timur region. International Journal of Advanced Science and Technology. Vol. 29 No. 06 
Michael Haenlein, 2010, Users of the world, unite! The challenges and opportunities of Social Media. Business Horizons.

Midtrans (Ecommerce Tips-Digital Marketing). Panduan Lengkap Menggunakan Youtube Ads untuk Bisnis Anda. Dikutip 24 September 2019 dari https://blog.midtrans.com/panduan-lengkap-memulai-youtube-ads-untukbisnis-anda.

Mudrajad, Kuncoro, 2013. Metode Riset untuk Bisnis dan Ekonomi, Edisi 4, Erlangga. Jakarta.

Nursyifa, A. (2018). Kajian Cultural Lag dalam Kehidupan Masyarakat Perkampungan Budaya Betawi Setu Babakan Pada Era Globalisasi. Jurnal Pendidikan Kewarganegaraan, 5(1), 1-24. Retrieved fromhttp://openjournal.unpam.ac.id/inde

Purwanti, P., Sarwani, S., \& Sunarsi, D. (2020). Pengaruh Inovasi Produk Dan Brand Awareness Terhadap Keputusan Pembelian Konsumen Pada Pt. Unilever Indonesia. Inovasi, 7(1), 24-31.

Rambat, Lupiyoadi, 2013, Manajemen Pemasaran Jasa Berbasis Kompetensi. (Edisi 3). Salemba Empat, Jakarta.

Rangkuti, Freddy, 2014. Analisis SWOT Teknik Membedah Kasus Bisnis, Gramedia Pustaka Utama. Jakarta.

Rulli Nasrullah, 2017, Media Sosial : Perspektif Komunikasi, Budaya, dan Sosioteknologi, Remaja Rosdakarya, Bandung.

RW Amelia, D Sunarsi. (2020). Pengaruh Return On Asset Dan Return On Equity Terhadap Debt To Equity Ratio Pada Pt. Kalbe Farma, Tbk. Ad Deenar: Jurnal Ekonomi dan Bisnis Islam 4 (01), 105-114D Sunarsi. (2014). Pengaruh Gaya Kepemimpinan, Motivasi dan Disiplin Kerja Terhadap Kinerja Pendidik. Universitas Pamulang

Siti Hidjatul Hidajah tahun 2012 Dinamika Ilmu Vol. 12 No. 1

Sunarsi, D. (2018). Analisis Motivasi Kerja Tenaga Pendidik Sukarela Pada Pusat Kegiatan Belajar Masyarakat (PKBM) Bimasda Kota Tangerang Selatan. Kreatif: Jurnal Ilmiah Prodi Manajemen Universitas Pamulang, 6(2), 53-65.

Sunarsi, D. (2019). Seminar Sumber Daya Manusia. Tangerang Selatan: Unpam Press

Sunarsi, D. (2020). Panduan Meningkatkan Kinerja Dan Kepuasan Guru. Kota Serang: Desanta Muliavisitama

Sunarsi, D., \& Asmalah, L. (2018). Pelatihan Manajemen Pengembangan Diri Bagi Penerima Beasiswa RZIS UGM Dan Dompet Shalahuddin Jogjakarta. Jurnal Pengabdian Dharma Laksana, 1(1), 51-60.

Sunarsi, D., \& Erlangga, A. (2020). The Effect of Leadership Style and Work Environment on the Performance of Stationary Pump Operators in the Water Resources Office of West Jakarta City Administration. International Journal of Advances in Social and Economics, 2(3).

Sunarsi, D., Kusjono, G., \& Nuryana, I. (2019). Pelatihan Manajemen Penguasaan Kelas Dan Pembuatan Bahan Ajar Bagi Tenaga Pengajar Sukarela Taman Belajar Kreatif Mekarsari. Jurnal Pengabdian Dharma Laksana, 2(1), 41-44. 
Sunarsi, D., Kustini, E., Lutfi, A. M., Fauzi, R. D., \& Noryani, N. (2019). Penyuluhan Wirausaha Home Industry Untuk Meningkatkan Ekonomi Keluarga Dengan Daur Ulang Barang Bekas. BAKTIMAS: Jurnal Pengabdian pada Masyarakat, 1(4), 188-193.

Sunarto, K. (2004). Pengantar Sosiologi. Jakarta: Lembaga Penerbit Fakultas Ekomoni UI.

Undang - Undang Republik Indonesia Nomor 12 Tahun 2012 Tentang Pendidikan Tinggi Pasal 4 Ayat 9 Tentang Tridharma Perguruan Tinggi

Yasha (August 20, 2019). Cara Membuat Facebook Ads:Panduan Lengkap 2019.

Dikutip 24 September 2019 dari https://www.dewaweb.com/blog/caramembuat-facebook-ads/.

Yuangga, K. D., \& Sunarsi, D. (2018). The Influence of Procrastination and Low Time Management on Student Self Efficacy (at MA Soebono Mantofani). PINISI Discretion Review, 2(1), 85-92.

Yuangga, K. D., Jasmani, J., \& Sunarsi, D. (2017). The Influence of Technology Determinism and Technology Literacy on Student Learning Outcomes (On MA Daarul Hikmah Pamulang). PINISI Discretion Review, 1(1), 23-30. 


\section{PANDUAN SINGKAT BAGI PENULIS JURNAL DHARMA LAKSANA}

Panduan penulisan ini dimaksudkan untuk menyeragamkan bentuk penulisan karya ilmiah yang dikirim penulis ke redaksi Jurnal Jenius, dengan panduan penulisan sebagai berikut :

1. Naskah ditulis dalam Bahasa Indonesia dengan Abstrak Bahasa Indonesia atau Bahasa Inggris dalam bentuk Font 12" dengan ukuran 1 Spasi dengan intisari tidak lebih dari 250 kata disertai 3 atau 4 kata kunci (keyword).

Naskah berupa Softcopy program MS maksimal 10 Halaman termasuk tabel dan gambar, spasi 1.

2. Sistematika penulisan disusun dengan urutan sebagai berikut :

a) Judul, nama dan alamat email penulis/peneliti tunggal.

b) Abstrak dan intisari, keyword dan kata kunci.

c) Batang Tubuh :

1). Pendahuluan, termasuk didalamnya intisari permasalahan

2). Metode Penelitian

3). Hasil dan Pembahasan

4). Kesimpulan dan Saran

5) Daftar Pustaka atau Referensi

6) Seluruh isi tersebut di buat dengan 1 kolom

3. Judul ditulis dalam bentuk font Times New Roman 12" dengan huruf besar kecil dicetak tebal dan ditempatkan ditengah halaman,, serta tidak lebih dari 18 kata.

4. Tulisan karya ilmiah dalam bentuk font Times New Roman 12" dengan ukuran spasi 1,0 spasi dalam bentuk kolom.

5. Gambar diberi nomor dan keterangan, sedangkan tabel diberi nomor dan keterangan diatasnya.

6. Penulisan persamaan matematika yang terdapat pada halaman naskah hendaknya menggunakan equation editor.

7. Daftar pustaka hanya memuat literature yang dirujuk dalam keterangan dan dicantumkan pada bagian akhir naskah dilakukan dengan memberikan nomor.

8. Margin atas dan kiri $4 \mathrm{~cm}$, kanan dan bawah $3 \mathrm{~cm}$, dan ukuran kertas A4.

9. Dokumentasi Foto kegiatan maksimal 5.

10. Email Redaksi : jpdl@unpam.ac.id/denoksunarsi@unpam.ac.id. 